\title{
Teias e tramas midiáticas: os discursos da Folha e da Veja na reconstituição do golpe contra Hugo Chávez
}

\author{
Gláucia da Silva Mendes
}

\section{Resumo:}

O controle exercido pelos conglomerados de mídia transnacionais sobre o setor de comunicações vem formando um ambiente propício à elaboração e à distribuição de produtos jornalísticos homogêneos, impregnados pela ideologia que rege o mundo globalizado. Tal propensão, por sua vez, é reforçada por um conjunto de fatores hegemônicos no processo de construção noticiosa. Neste contexto é que o presente artigo analisa a cobertura realizada pelo jornal Folha de S. Paulo e pela revista Veja sobre o golpe que afastou Hugo Chávez da presidência venezuelana por 48 horas, em abril de 2002.

\section{Palavras Chave:}

conglomerados midiáticos transnacionais; newsmaking; ideologia.

\begin{abstract}
:
The control exercised by transnational media corporations over the communication field has formed a propitious environment to the elaboration and distribution of homogeneous journalistic products, impregnated by globalized world ideology. That tendency is reinforced by a set of hegemonic factors in the process of making news. In this context, this paper analyzes the coverage made by the newspaper Folha de S. Paulo and the magazine Veja about the coup that kept Hugo Chávez away from Venezuela's presidency during 48 hours, in April 2002.
\end{abstract}

\section{Keywords:}

transnational media corporations; newsmaking; ideology.

\section{Introdução}

Um dos maiores escândalos da mídia mundial. Para o sociólogo brasileiro Emir Sader (2004), essa é a sentença que melhor caracteriza a atuação dos meios de comunicação venezuelanos durante o golpe arquitetado pela oposição política, em abril de 2002, contra o governo democraticamente eleito de Hugo Chávez.

Embora evidencie o ineditismo e a relevância do fenômeno, tal avaliação circunscreve-se à análise dos produtos informativos elaborados em âmbito nacional. Ela não considera o acontecimento sob a perspectiva de sua inserção no circuito mundial de comunicação - abordagem que, em um planeta marcado pela globalização dos diferentes setores econômicos, demonstra-se também essencial.

Com a finalidade de contribuir para o desenvolvimento de reflexões dessa natureza, este artigo investiga o recente momento da história dos meios de comunicação, adotando como foco de observação o noticiário produzido pela grande imprensa brasileira sobre o golpe contra Hugo Chávez.

Para viabilizar a análise, selecionamos como objeto de estudo a cobertura realizada pelo jornal Folha de S. Paulo e pela revista Veja. Ao material produzido pelos dois meios de comunicação foi aplicada uma 
metodologia que incluiu tanto a observação das variáveis técnico-profissionais e dos elementos discursivoideológicos utilizados quanto o confronto do noticiário assim produzido com relatos e notícias que desvelassem a atuação da mídia venezuelana no episódio.

Com a finalidade de contemplar todos os acontecimentos diretamente envolvidos com o golpe, foram definidos períodos de observação que abarcassem desde o noticiário sobre a greve geral deflagrada pela oposição até aquele produzido sobre o retorno de Chávez à presidência. Da revista, foram submetidas à análise as edições dos dias 10, 17 e 24 de abril; do jornal, todos os números publicados entre 10 e 15 de abril, inclusive.

\section{A produção de notícias no contexto dos oligopólios midiáticos}

As fusões e as articulações empresariais engendradas no mundo com o surgimento do capitalismo monopolista assumiram novos contornos na década de 70. O advento da doutrina neoliberal e do processo de globalização abriram caminho ao estabelecimento de parcerias transnacionais e à realização de investimentos em nível mundial. A expansão das atividades sócio-econômicas, sob essa nova orientação, alterou a configuração de diversos setores. Uma das áreas atingidas foi a de comunicação: "no decorrer dessa reorganização, o setor de publicidade e dos meios de comunicação transformou-se no domínio das novas redes de agências com dimensões planetárias (...), assim como o pedestal dos novos grupos multimídia" (MATTELART, 1994: 249).

Se, por um lado, a formação desse tipo de rede desponta como uma estratégia de fortalecimento das grandes empresas de comunicação no mercado global, por outro, ela dificulta a emergência e a sobrevivência de médias e pequenas organizações no ramo, comprometendo, assim, a pluralidade de visões sobre o mundo: "a concentração e a conglomeração deitam raízes, dificultando cada vez mais o equilíbrio de forças no campo da comunicação e, por extensão, a pluralidade de visões de mundo que emergiria com fontes informativas descentralizadas.” (MORAES, 1998: 105)

A conseqüência imediata dessa configuração do setor midiático, no jornalismo, é a formação de um ambiente favorável à elaboração de produtos noticiosos consensuais, calcados na visão de mundo que mantém a ordem estabelecida. Essa propensão, por sua vez, é reforçada pelo contexto no qual a prática jornalística desenvolvese.

Tal quadro laborativo resulta de um conjunto de fatores organizativo-burocráticos e elementos de ordem comunicativo-expressiva que induzem os profissionais do ramo a um trabalho similar de filtragem e manipulação dos acontecimentos (WOLF, 1995). Dentre os critérios organizativo-burocráticos que pesam na definição dos acontecimentos passíveis de noticiabilidade, destaca-se, especialmente no que diz respeito à editoria internacional, o fato de ser publicado nos despachos produzidos por agências de notícias.

Uma das conseqüências da utilização, em grande volume, do material internacional elaborado por essas fontes é a transformação da imprensa nacional e local em um satélite do mercado exterior, mais especificamente de seis agências que hoje respondem por boa parte das notícias internacionais veiculadas no mundo (ROSSI, 1994).

Com relação aos elementos comunicativo-expressivos, assumem relevo na conformação do noticiário os critérios de noticiabilidade próprios a cada meio de comunicação, pois são eles que, em última instância, definem o aspecto final dos produtos informativos. 
No que concerne ao jornalismo impresso, um dos principais parâmetros norteadores da produção noticiosa é a submissão dos fatos a uma estrutura narrativa que ordena os eventos “(...) não por sua seqüência temporal, mas pelo interesse ou importância decrescente, na perspectiva de quem conta e, sobretudo, na suposta perspectiva de quem ouve." (LAGE, 1987: 21).

Além das variáveis organizativo-burocráticas e comunicativo-expressivas hegemônicas na área jornalística, outro fator que exerce influência sobre os noticiários - e, portanto, participa de sua composição final - é o posicionamento ideológico dos proprietários dos veículos de comunicação e, quiçá, de seus profissionais. Enquanto manifestação de indivíduos pertencentes a grupos sociais, cujos posicionamentos determinam a visão de mundo de seus membros, todo e qualquer discurso - inclusive o jornalístico - é ideologicamente marcado: "a cada formação ideológica corresponde uma formação discursiva (...). É com essa formação discursiva assimilada que o homem constrói seus discursos, que ele reage lingüisticamente aos acontecimentos" (FIORIN, 2004: 32).

As determinantes ideológicas incidentes sobre um discurso, seja ele jornalístico ou não, encontram-se arraigadas tanto a estruturas sintáxicas presentes na arquitetura textual quanto às redes de temas e figuras traçadas no interior do texto com o propósito de construir a trama significativa (FIORIN, 2004).

\section{O golpe contra Chávez na perspectiva dos meios de comunicação venezuelanos}

A articulação entre produção jornalística uniforme e defesa ideológica, operada em um setor caracterizado pela interconexão entre megacorporações transnacionais, desponta como o cenário no qual ocorreu a cobertura realizada pelos meios de comunicação venezuelanos sobre o golpe que manteve Hugo Chávez afastado do poder durante dois dias. Esse cenário, conseqüentemente, condiciona também a repercussão do acontecimento no Brasil.

A inserção do fenômeno nesse contexto deve-se ao fato de ambos os países encontrarem-se fortemente integrados ao mercado global de comunicação: tanto o Brasil quanto a Venezuela figuram entre as nações detentoras dos maiores conglomerados midiáticos latino-americanos, organizações que muitas vezes atuam como parceiras em projetos de âmbito continental (MORAES, 1998).

Conforme explicitado, o pertencimento a grupos sociais que se sustentam sobre uma mesma ideologia e as inter-relações estabelecidas entre megacorporações de mídia, cujos produtos advêm, sobretudo, da repetição cotidiana de rotinas padronizadas, abrem espaço para a propagação de discursos homogêneos.

Diante desse quadro, é de se esperar, portanto, que a essência da cobertura realizada pelos meios de comunicação venezuelanos sobre o golpe contra Hugo Chávez tenha sido replicada pelos veículos impressos brasileiros. Para avaliar a pertinência ou não dessa hipótese, faz-se necessário elucidar alguns aspectos-chave dos discursos jornalísticos elaborados pelos grandes meios de comunicação venezuelanos sobre o governo Hugo Chávez e, em especial, sobre os acontecimentos de abril.

A observação de trechos de notícias veiculadas em momentos anteriores ao golpe permite divisar como o governo Chávez vinha sendo retratado pelos grandes meios de comunicação de seu país:

O nosso presidente está fascinado, de uma forma sexual tipo freudiana, pelo senhor Fidel Castro. O 'chavismo' apóia-se, cada vez mais, na violência, na medida em que perde popularidade. São parecidos com as forças de choque de Mussolini e Hitler. (BARTLEY; O’BRIAIN, 2003) 
A parcialidade dos veículos, evidenciada por essas avaliações, torna-se inconteste diante da descrição realizada por André Izarra, ex-chefe de produção da uma das principais emissoras de televisão venezuelana, sobre a forma como foi reconstituído o massacre dos manifestantes de 11 de abril, episódio exaustivamente reiterado pelos noticiários venezuelanos:

O canal Venevisión tinha uma câmera em frente ao palácio que registrava imagens de gente [partidários de Chávez] atirando da ponte. Pensamos que atiram contra a marcha que não está visível. Mas vemos que eles mesmos estão se abaixando, estão se protegendo de tiros na sua direção. Mas na TV não procuramos saber o que acontecia, simplesmente os condenamos e as imagens foram manipuladas e repetidas várias vezes para dizer que o "chavismo" tinha assassinado gente e era culpado pelo massacre de Caracas. (BARTLEY; O’BRIAIN, 2003)

A destituição de Chávez, justificada, em grande medida, por essa manipulação midiática, foi saudada pelos meios de comunicação venezuelanos com novas diretrizes de produção noticiosa, como relata André Izarra: "A censura foi estabelecida na sexta-feira de manhã, quando nos proibiram de entrevistar qualquer personagem do 'chavismo'. Zero 'chavismo"”. (BARTLEY; O’BRIAIN, 2003).

Assim, durante o tempo em que o presidente manteve-se afastado do poder, os grandes veículos nacionais atuaram como porta-vozes do "governo de transição", inclusive omitindo informações sobre a situação real. É o que demonstra, por exemplo, a postura adotada pela mídia venezuelana diante dos panelaços e das demais manifestações pró-chavistas que se alastraram pelo país em 13 de abril:

A programação das rádios e televisões, no dia anterior tão pródiga em exaltar os feitos e atos do 'governo de transição', emudeceu sobre temas políticos. Passaram a exibir desenhos animados e programas de auditório, como se reinasse uma tranqüilidade absoluta em todos os estados. (MARINGONI, 2004: 40)

\section{O noticiário do jornal Folha de S. Paulo}

A editoria internacional da Folha de $\mathrm{S}$. Paulo começou a abordar os acontecimentos venezuelanos relacionados ao golpe contra Hugo Chávez no dia 10 de abril de 2002, em função da greve deflagrada pela PDVSA, juntamente com a Central Venezuelana de Trabalhadores (CTV) e a Fedecámaras, no dia anterior.

Em virtude do amplo espaço dedicado ao assunto pelo jornal, entre 10 e 15 de abril - foram publicados 43 textos no período especificado -, adotou-se como objeto de investigação uma amostra correspondente a $32 \%$ do universo total. As matérias selecionadas foram aquelas de maiores dimensões, pois, ao menos teoricamente, elas seriam capazes de fornecer mais subsídios para a pesquisa.

Ao analisar essas notícias, torna-se possível verificar a persistência de técnicas produtivas jornalísticas e elementos comunicativo-expressivos que, por permearem praticamente todo o noticiário observado, permitem desvelar posições e ideologias subjacentes à cobertura dos acontecimentos realizada pelo veículo.

Uma das práticas recorrentes diz respeito à captação das informações. Ao realizar essa rotina profissional, a Folha valeu-se, sobretudo, dos despachos de agências internacionais. Mesmo após o envio de um correspondente a Caracas, em 13 de abril, o jornal continuou adotando esse tipo de material como parâmetro de produção noticiosa. 
Tal decisão corrobora a assertiva de Wolf (1995), segundo a qual a intensa utilização dos materiais de agência, inclusive por correspondentes, praticamente uniformiza as definições sobre os fatos e os aspectos que merecem ser noticiados. Ela também atesta a validade da explanação de Rossi (1994), ao provar que a cobertura de acontecimentos internacionais realizada «in loco» também se submete aos ditames das agências informativas de âmbito planetário.

A versão propalada pelas agências internacionais consistiu, portanto, no pano de fundo em que se operou a reconstituição dos fatos venezuelanos realizada pelo jornal brasileiro. Conjugada a outras técnicas profissionais e aos investimentos de ordem lingüística, ela também auxiliou na definição do significado dos acontecimentos. Essa acepção, em sua essência, procurou justificar a ação dos militares como resultado das atitudes de Chávez e classificá-la não como um golpe militar tradicional, mas sim como um ato em prol do anseio popular.

Para a construção de tal sentido, confluíram procedimentos como a escolha léxica realizada com o intuito de descrever o perfil de Hugo Chávez. Expressões como "estilo autocrático" (FORERO, 2002), "coronel que compra brigas" (APOIO..., 2002) e profere "discursos agressivos e ameaçadores" (NOVO..., 2002) criaram a imagem de um presidente autoritário, que age de acordo com suas vontades e disposições pessoais.

Também a administração de Chávez foi, a todo momento, alvo desse tipo de construção. Ela foi substancialmente caracterizada como um governo de "estilo populista", regido por "políticas de esquerda" (FORERO, 2002), cujo teor é definido pela "aproximação cada vez maior com o ditador cubano, Fidel Castro" (APOIO..., 2002).

Quando confrontadas com os adjetivos atribuídos a Chávez e a seu governo por determinadas fontes consultadas pelo jornal, tais qualificações permitem entrever a existência de uma ideologia subjacente às construções. É o que evidencia, por exemplo, as declarações de Chuca Taberna de Obregón.

Esposa de um bem-sucedido empresário de Caracas, a venezuelana declarou à Folha que "sentia vergonha de lembrar que os amigos do presidente do meu país são Fidel Castro e Sadam Hussein”, queixou-se do "discurso de ódio" de Chávez e deixou transparecer sua admiração por Vicente Fox, por ser um "empresário de sucesso, parceiro dos maiores líderes mundiais" (AITH, 2002c).

A alusão a aspectos similares do suposto perfil de Chávez, empreendida pela fonte e pelo periódico brasileiro, sob uma mesma perspectiva - todos eles são apresentados como defeitos -, permite entrever uma comunhão ideológica entre o discurso dos diferentes atores, o que, conforme vislumbrado em Fiorin (2004), representa um indício do pertencimento de ambos a um único grupo social.

Diante dessas considerações, torna-se possível afirmar que, por se encontrar vinculada a ele, a Folha representa, com seu discurso, o «status» quo protagonizado pelo neoliberalismo e pelas classes dominantes que o conduzem. Tal assertiva, por sua vez, corrobora a hipótese de Moraes (1998), segundo a qual os produtos culturais difundidos pelos conglomerados de mídia submetem-se às forças econômicas globais.

Os percursos figurativos construídos pelo veículo mediante a articulação dos adjetivos supracitados serviram como respaldo a argumentos que corroborassem o significado do golpe subjacente ao noticiário da Folha. Uma das afirmações sustentadas por eles foi a suposta perda de popularidade de Chávez entre civis. Esta foi apresentada como uma conseqüência do fracasso das políticas adotadas pelo presidente venezuelano (AITH, 2002b).

Vale ressaltar que, ao lançar esse argumento, o jornal brasileiro não apresentou dados concretos e nem estatísticas de natureza sócio-econômica capazes de demonstrar os resultados insatisfatórios dos programas 
chavistas. Ele apenas mencionou pesquisas de opinião que apontavam nessa direção. Citação essa que, aliás, foi muito superficial: o jornalista não explicitou a procedência dos dados, deixando dúvidas sobre a confiabilidade e a isenção do órgão responsável pelas asserções.

Tais dados, cuja credibilidade é passível de contestação, respaldaram uma assertiva-chave na definição do significado dos acontecimentos empreendida pela Folha, muito bem expressa na fala do analista político Alfredo Keller: "[a queda de Chávez] não foi um golpe das Forças Armadas imposto ao povo, mas uma manifestação popular contra o governo que teve apoio das Forças Armadas" (APOIO..., 2002).

A adoção desse ponto de vista por parte do periódico fica patente quando se observam determinados investimentos semânticos e sintáxicos realizados pelo jornal ao se referir à manifestação de 11 de abril, que culminou com o afastamento de Chávez no dia seguinte.

"Megaprotesto", "um dos maiores atos contra Chávez” (CHÁVEZ..., 2002b). Assim a principal matéria publicada pela Folha no dia 12 de abril dimensionou o movimento oposicionista que cruzou as ruas de Caracas em direção ao palácio presidencial. Definições essas que, por sua vez, fundamentaram argumentações subseqüentes, como a expressa pela construção sintáxica "os militares que deram o golpe, apoiados por amplos setores da sociedade civil" (AITH, 2002b).

Para que fosse transmitida a imagem de impopularidade de Chávez, nesse episódio em específico - a manifestação de 11 de abril -, o jornal valeu-se também de uma rotina operacional própria do jornalismo: a seleção/edição de informações empreendida durante o processo de «newsmaking». Ele omitiu a existência e, por conseguinte, a dimensão - de uma multidão pró-chavista que, no mesmo instante, manifestava apoio ao presidente venezuelano.

No que concerne à manifestação, outro aspecto discursivo que merece ser destacado diz respeito ao desdobramento do ato: o massacre registrado na ponte Llaguno. Ao reportar o acontecimento, a Folha utilizou-se da palavra "repressão" (CHÁVEZ..., 2002b) e acabou, assim, por condicionar sua leitura.

Mesmo sem apresentar evidências concretas da responsabilidade de Chávez - para validar a assertiva, foram citados apenas os depoimentos de um general rebelado e de fontes anônimas -, o jornal definiu a resposta à manifestação com essa palavra, cujo significado reforça a idéia de que o presidente fora o culpado pelo episódio e, sobretudo, reitera a versão apresentada pelos meios de comunicação venezuelanos.

Outra notícia que aponta para essa direção - a convergência da cobertura realizada pela Folha com a venezuelana - é o relato sobre a deposição de Chávez e a conseqüente ascensão de Carmona ao poder (AITH, 2002b). Representantes do governo deposto e simpatizantes chavistas foram praticamente excluídos do rol de fontes consultadas nesta notícia.

A apresentação dos pontos de vista dessas fontes sobre os acontecimentos ficou restrita à controversa renúncia de Chávez. Na exposição de assuntos polêmicos, como o massacre ocorrido em Miraflores e a origem da sublevação militar, imperou a voz oposicionista.

Tal procedimento assemelha-se à política explicitamente adotada pelos meios de comunicação venezuelanos a partir do dia 12. Conforme relatado, desse momento em diante, definiu-se como linha editorial a exposição única e exclusiva de declarações dos militares e dos representantes do novo governo.

A uniformização das práticas jornalísticas vislumbrada tanto no relato sobre o massacre da ponte Llaguno quanto na exclusão das fontes chavistas dos noticiários, emerge como um importante indício das relações estabelecidas entre as grandes empresas de mídia no mundo globalizado, às quais alude Moraes (1998), e da 
conseqüente formação de discursos marcados pelo consenso ideológico.

Além da quase total exclusão de fontes pró-chavistas, o noticiário posterior ao golpe também foi marcado por um tom acrítico em relação aos novos acontecimentos. Embora as primeiras ações empreendidas por Carmona guardassem um certo autoritarismo - o empresário dissolveu instituições e cancelou leis (AITH, 2002b) -, a Folha optou pela elaboração de um relato isento de ponderações que alertassem para os rumos assumidos pelo governo de transição.

Nas matérias do dia 13 de abril submetidas à análise, o jornal praticamente ignorou o significado subjacente a esses atos, preferindo avaliar o presente e o futuro da Venezuela mediante o destaque de promessas do empresário que atribuíam ao governo de transição um caráter democrático: "Carmona (...) promete convocar eleições presidenciais e legislativas em breve" e "Carmona (...) prometeu respeitar as liberdades civis: "Todos sentirão que existe liberdade, pluralismo e respeito ao Estado de Direito"” (AITH, 2002b).

A exaltação dos feitos de Carmona conjugou-se com a minimização da força dos protestos que emergiram no país para exigir o retorno de Chávez, criando a impressão de que a deposição realmente satisfazia o anseio do povo. "A não ser por poucos panelaços e manifestações esparsas (...) os pobres, a quem Chávez dizia dedicar seu governo, não saíram às ruas para defendê-lo" (AITH, 2002c).

Tal argumentação foi mantida até mesmo nos primeiros momentos após a queda do governo transitório. Para sustentá-la no noticiário de 14 de abril, o jornal valeu-se da autoridade do analista Emilio Figueredo Planchart, para quem a mobilização que reconduziu Chávez ao poder não foi articulada em prol do presidente deposto, mas sim contra os métodos utilizados para destituí-lo (AITH, 2002a).

\section{A cobertura da revista Veja}

Entre os dias 10 e 24 de abril de 2002, considerável espaço da revista Veja foi ocupado pelos acontecimentos venezuelanos: das três edições deste período, duas publicaram matérias relativas ao assunto. A primeira, com data de 17 de abril, trouxe uma reportagem que ganhou manchete na capa; na segunda, de 24 de abril, o tema motivou o editorial, marcou presença na entrevista das páginas amarelas e ganhou uma matéria de três páginas na editoria internacional.

A observação das técnicas jornalísticas empregadas, das escolhas léxicas e sintáxicas realizadas, dos dados e dos argumentos elucidados com a finalidade de compor todo esse material evidencia como, respeitadas as especificidades de cada meio, o discurso construído pela revista se assemelhou àquele produzido pela Folha.

Assim como o jornal, Veja empreendeu operações semânticas que, uma vez articuladas, procuraram desqualificar o governo Chávez, visando justificar a ação inconstitucional que o afastou do poder e criar a impressão de que esta respondia aos anseios da população venezuelana.

É o que atesta, por exemplo, a caracterização de Chávez e seu governo, empreendida na primeira matéria publicada pelo periódico sobre o assunto (LOURES, 2002). "Presidente-coronel", "retórica revolucionária", "promessas populistas", "bravatas esquerdistas": estas foram algumas das expressões que compuseram o repertório de qualidades chavistas.

A imagem do governo Hugo Chávez construída mediante o emprego de tais figuras foi reforçada por dados e argumentos apresentados no decorrer do texto. Como exemplos desse tipo de operação vislumbram-se a afirmação de que mudanças de leis e autoridades eram regidas pelo humor de Chávez e a menção ao aumento 
do salário mínimo de 190 para 230 dólares. Enquanto a primeira assertiva reitera o autoritarismo do governo venezuelano, a segunda pretende evidenciar seu caráter populista.

Unidas por um único percurso temático, essas e outras informações suscitadas com o mesmo intuito concorreram para a formação da imagem de um "governo caótico", comandado por um presidente cujos mandos e desmandos já não eram suportados nem pelo seu povo - a reportagem afirmava que, de $80 \% \mathrm{em}$ 1999, a popularidade de Chávez caíra para 30\% em fevereiro de 2002.

Embora pairassem dúvidas sobre a confiabilidade dos dados - a revista não mencionou a fonte da qual obtivera tal informação - as estatísticas apresentadas forneceram a justificativa necessária para legitimar o golpe como uma ação resultante de um descontentamento generalizado - e, portanto, como a concretização da vontade dos cidadãos venezuelanos -, e não como um ato inconstitucional comandado por militares e representantes da alta burguesia.

A atribuição dessa carga semântica ao episódio envolveu ainda o uso de outra estratégia: a omissão de informações, empreendida no processo de produção jornalística. Na reconstituição dos acontecimentos do dia 11, cujos desdobramentos conduziram ao afastamento de Chávez, a reportagem citou a marcha que reunira 200.000 civis contra o governo e os ataques que a atingira em frente à sede da presidência da República atribuindo-os ao presidente venezuelano -, mas preteriu informações sobre a existência e a dimensão da manifestação pró-governo, que também fora vitimada pelo massacre.

Conforme permite vislumbrar a exposição realizada no presente artigo, o relato construído pela Veja sobre esse dramático momento muito se assemelha àquele veiculado pela Folha de $\mathrm{S}$. Paulo e pelos grandes meios de comunicação venezuelanos. Tal convergência dos noticiários é um importante indício da uniformização dos produtos jornalísticos, provocada tanto pelas práticas profissionais hegemônicas quanto pelas interconexões entre megacorporações de mídia no mundo globalizado.

A descriminalização do movimento que afastou Chávez do poder, iniciada com as construções supracitadas cuja finalidade primordial era criar uma imagem de insatisfação popular para com o governo -, completou-se com investimentos léxicos que atenuaram a natureza do acontecimento. Exemplo emblemático dessa operação é a definição da articulação militar responsável pela concretização do ato como uma "rebelião" que pressionou Chávez à renúncia, em vez de um "golpe" que o depôs de forma autoritária e unilateral.

O processo de significação empreendido nesta primeira matéria, mediante todas as articulações elucidadas, foi ainda reforçado por asserções de terceiros: a revista recorreu a três fontes para atribuir um tom de verdade a seu discurso, sendo todas elas portadoras de opinião contrária ao governo venezuelano. Ao não dedicar espaço à manifestação de partidários de Chávez, o veículo desrespeitou a prática jornalística de ouvir os dois lados envolvidos em uma história para posicionar-se perante os acontecimentos.

Ao observar a edição subseqüente da Veja, que trata do retorno de Chávez, é possível verificar a persistência dessa linha discursiva adotada para reconstruir o golpe. Embora o editorial da revista tenha qualificado a recondução do presidente venezuelano ao poder como uma vitória da democracia (UMA VITÓRIA..., 2002), a matéria principal (O CORONEL..., 2002) e a entrevista com o especialista em América Latina, Peter Hakim, (HAKIM, 2002) mantiveram o mesmo tom anterior.

Hakim, por exemplo, emitiu opiniões que sustentaram argumentos utilizados na edição passada e na presente para definir os acontecimentos e caracterizar o governo. O especialista confirmou a informação, veiculada no número anterior, de que a política de Chávez era calcada no populismo e fez avaliações que serviram de ponto de partida para a construção discursiva da matéria publicada no mesmo número da entrevista: as assertivas de que o governo Chávez agravou a divisão social do país e de que, para alterar essa situação, o presidente 
deveria adotar uma política conciliatória (HAKIM, 2002).

As consonâncias produzidas a partir desse diálogo estabelecido entre os textos permitem entrever a persistência de uma mesma ideologia subjacente a ambos os discursos. As nuances dessa ideologia tornam-se evidentes a partir de uma simples análise do perfil do entrevistado: como a própria Veja esclarece, Peter Hakim era, na época, conselheiro do Banco Mundial, uma das entidades financeiras que vêm patrocinando a propagação dos princípios neoliberais pelo mundo.

Avaliando tal informação sob a perspectiva de Fiorin (2004), torna-se possível afirmar que, ao compartilhar dos mesmos argumentos utilizados por uma personagem estreitamente ligada a uma instituição financeira que figura entre os representantes máximos do sistema neoliberal, a revista apresenta-se como também um membro desse grupo e coloca-se, em função disso, como uma defensora dos pontos de vista sustentados por ele.

A manutenção dos argumentos anteriormente lançados pela revista acabou mesmo por exigir outra explicação para o desfecho dos acontecimentos venezuelanos. Como a atribuição do retorno de Chávez à vontade popular e à articulação de militares fiéis minaria um argumento central do discurso - o descontentamento geral para com o governo - a revista apresentou o ato como uma medida urgente dos militares golpistas para deter Carmona, que estava se relevando um político muito mais anti-democrático do que Chávez (O CORONEL..., 2002).

\section{Conclusão}

A forte integração da mídia venezuelana ao circuito global de comunicação - o país detém um dos principais conglomerados latino-americanos do ramo - facilitou a disseminação do discurso produzido sobre o golpe de abril de 2002 para diferentes partes do mundo. Isso ocorreu em função das alianças mantidas com outras megacorporações transnacionais e da comunhão ideológica com os membros desse grupo.

Uma das nações a replicar a visão - e a versão - dos acontecimentos propalada pelas grandes empresas de comunicação da Venezuela foi o Brasil. Os principais veículos impressos do país, também pertencentes a conglomerados de expressão nos cenários nacional e internacional, publicaram variados textos a respeito do assunto, elaborados sobre um mesmo substrato discursivo.

Baseando-se, sobretudo, em despachos de agências facilmente inseríveis nos processos de produção noticiosa voltados à racionalização de recursos, o jornal diário Folha de S. Paulo e a revista semanal Veja construíram noticiários calcados nas imagens do episódio e do presidente Chávez difundidas pela mídia venezuelana.

A similar manipulação de técnicas jornalísticas e a recorrência às mesmas estratégias discursivas empreendidas por esses meios de comunicação com a finalidade de retratar os acontecimentos venezuelanos em consonância com o discurso advindo deste país - contribuíram para a disseminação, no Brasil, de uma visão estereotipada do governo Chávez, impregnada por um viés ideológico conservador, hegemônico entre as grandes corporações das mídias brasileira e mundial. 


\section{Bibliografia:}

AITH, Marcio. "Carmona renuncia e vice de Chávez assume”. Folha de S. Paulo, Mundo, 14/04/2002a. Mundo. Disponível: www1.folha.uol.com.br/fsp/mundo/ft1404200201.htm. Acesso em: 19/01/2006. . "Novo presidente dissolve poderes". Folha de S. Paulo, Mundo, 14/04/2002b. Disponível: www1.folha.uol.com.br/fsp/mundo/ft1304200201.htm. Acesso em: 19/01/2006. . "Ricos festejam queda do presidente". Folha de S. Paulo, Mundo, 14/04/2002c. Disponível: www1.folha.uol.com.br/fsp/mundo/ft1404200204.htm. Acesso em: 19/01/2006. APOIO militar evaporou com apoio popular. Folha de S. Paulo, Mundo, 13/04/2002. Disponível: www1.folha.uol.com.br/fsp/mundo/ft1304200204.htm. Acesso em: 19/01/2006. A REVOLUÇÃO não será televisionada. Direção: Kim Bartley e Donnacha O’Briain. Produção: David Power. Produtora: Power Picture associada à Agencia de Cinema da Irlanda. Irlanda: 2003, 74 min., son., color.

CHÁVEZ enfrenta rebelião após megaprotesto. Folha de S. Paulo, Mundo, 12/04/2002b. Disponível: www1.folha.uol.com.br/fsp/mundo/ft1204200201.htm. Acesso em: 19/01/2006.

FIORIN, José Luiz. Linguagem e ideologia. 8a . ed. São Paulo: Ática, 2004 (Série Princípios).

FORERO, Juan. “Apoio militar a presidente é incerto”. Folha de S. Paulo, Mundo, 13/04/2002. Disponível: www1.folha.uol.com.br/fsp/mundo/ft1204200204.htm. Acesso em: 19/01/2006.

HAKIM, Peter. Fora do mapa. Washington: 2002. Entrevista concedida a R. J. Lores e publicada em $24 / 04 / 2002$.

LAGE, Nilson. Estrutura da notícia. 2a . ed. São Paulo: Ática, 1987.

LOURES, Raul Justes. “O falastrão caiu”. Veja, v.35, n.15, p.42-45, abril de 2002.

MARINGONI, Gilberto. A Venezuela que se inventa: poder, petróleo e intriga nos tempos de Chávez. São Paulo: Fundação Perseu Abramo, 2004.

MATTELART, Armand. Comunicação mundo: história das idéias e das estratégias. Rio de Janeiro: Vozes, 1994 (Coleção horizontes da globalização).

MORAES, Dênis de. Planeta mídia: tendências da comunicação na era global. Campo Grande: Letra Livre, 1998.

NOVO presidente é líder do empresariado. Folha de S. Paulo, Mundo, 13/04/2002. Disponível: www1.folha.uol.com.br/fsp/mundo/ft1304200214.htm. Acesso em: 19/01/2006.

O CORONEL voltou. Veja, v.35, n.16, p. 50-52, abril de 2002.

ROSSI, Clóvis. O que é jornalismo. 10ª . ed. São Paulo: Brasiliense, 1994.

SADER, Emir. Venezuela: o escândalo da mídia. Santos: 2004. Entrevista concedida a Rosângela Gil. Disponível: www.piratininga.org.br/entrevistas/emirsader-abril2004.html. Acesso em: 10/06/2005. 
UMA VITÓRIA da democracia. Veja, v.35, n.16, p.15, abril de 2002.

WOLF, Mauro. Teorias da comunicação. 4a . ed. Lisboa: Presença, 1995.

\section{Notas:}

Trabalho apresentado no II Intercom Júnior, evento integrante do XXIX Congresso Brasileiro de Ciências da Comunicação (Intercom, 2006) e agraciado com o Prêmio Vera Giangrande, concedido aos melhores trabalhos de iniciação científica apresentados.

\section{Mini Currículo :}

Mestranda do Programa de Pós-graduação em Comunicação da Universidade Federal de Juiz de Fora (UFJF) e bacharel em Comunicação Social, com habilitação em Jornalismo, pela UFJF. E-mail:

gs_mendes@yahoo.com.br 